\title{
Addressing Capacity Building of Disaster Prevention and Mitigation in Tourism Resilience
}

\author{
Wen Bao* and Tao Dai \\ School of Management, Chengdu University of Information Technology, Chengdu, P.R. China, 610103 \\ *Corresponding author. Email: baowen@cuit.edu.cn
}

\begin{abstract}
Reducing vulnerability and enhancing resilience have unique value implications in capacity-building for disaster prevention and mitigation in tourism. To strengthen resilience in the tourism sector, this study aims to better understand the current disaster prevention and mitigation capacities and needs of the tourism resilience, and make recommendations on how to improve these capacities and be most effective in reducing disaster risks. The integration of capacity-building of disaster prevention and reduction and resilience is a realistic need to address the tourism disasters risk management. On the one hand, from the perspective of disaster management, the construction path of tourism risk management is designed. On the other hand, from the four aspects of risk identification, risk assessment, risk resolution and the whole process, the relief strategy to improve the resilience of tourism can provide a reference for tourism risk management ideas and path reference. It sets out a people-cantered plan to strengthen the resilience of people, businesses and communities that relevant to tourism sector.
\end{abstract}

Keywords: Tourism, Meteorological disasters, Prevention and mitigation, China.

\section{INTRODUCTION}

Tourism contributes $4.56 \%$ of GDP in 2019 and is responsible for tens of millions of jobs and also one of the fastest grows sectors in China. Tourism sector is trapped in a vicious and self-fulfilling cycle of disasterrespond- recover- repeat. Strengthen resilience can mitigate the impact of disasters or emergencies on tourism, the core of which is to emphasize the adaptive and self-recovery capacity of tourism to disasters or emergencies. From the 19th century to the present, capacity-building has been gradually perfected in the field of tourism risk management, and the ability to resist, restore, absorb and adapt is put forward, the core of which is to emphasize the ability of to survive and develop in the face of crisis and pressure, to penetrate the concept of resilience into the development plan of tourism, and to cultivate the sense of crisis and responsibility of tourism practitioners. With the continuous improvement of the concept of resilience in the field of tourism risk management, it can be found that the tourism industry turns crisis and pressure into opportunities, and gradually realizes that by improving the innovation ability of resilience and strengthening the leading position of resilience management in tourism risk, it is the core position to solve the crisis and pressure of tourism at this stage.

Improving the resilience of tourism requires reducing its vulnerability. In the field of tourism resilience, vulnerability refers to the consideration of disaster exposure and its susceptibility and resilience scale. From this point of view, tourism vulnerability is a measure of the degree to which tourism may lead to damage to tourism practitioners and degradation of tourism resources when faced with external environmental pressures and disturbances [1]. Tourism vulnerability is the instability and inherent destructiveness of tourism in the process of disaster response caused by the inadequacy of tourism's ability to resist risks in high-risk situations. In the face of challenges and risks to the tourism industry, if pre-disaster prevention reduces investment and other ways, often do not take the behaviour strategy to resist external interference, adjust the structure of the system and turn the challenge into opportunity [2]. The concept of capacity-building for disaster prevention and mitigation is applied cleverly to enhance the resilience of tourism, and the two cross and merge to promote the diversified development of tourism. By increasing the resilience of tourism and optimizing the allocation of resources, the vulnerability of tourism can be reduced and 
disaster risk response capacity at high risk can be enhanced [3].

\section{TOURISM RESILIENCE AND DISASTER RISK MANAGEMENT}

Strengthening resilience can maintain the stability of tourism function, which will inevitably attract more capital investment and resource support, and through the form of government guidance and multi-subject cooperation, so as to ensure the regional infiltration of resilience management, and ultimately improve the tourism industry's ability to cope with disasters, adaptability and disaster recovery capacity. Therefore, the resilience characteristics of tourism itself are an important reference point for tourism disaster prevention and mitigation capacity-building, and a new way for tourism to resist risks and pressures and complete its own system remodelling, identify risk factors, absorb external threats and other objectives [4].

First of all, in the stage of conventional management of tourism disaster risk, due to the imperfection of risk management methods and laws and regulations, it will inevitably lead to the management of tourism disaster risk vulnerability facing the practical problems of unstable investment cost, unclear risk identification, irregular risk detection, unscientific accident control, etc., and the risk and disaster expansion dilemma caused by the lag of development, such as disaster monitoring, safety training, publicity and education. Therefore, in the stage of conventional management of tourism disaster risk, the overall advantages of implementing tough governance outweigh the disadvantages, and it is challenging under the premise of imperfect risk management policy and inaccurate disaster prevention.

Secondly, in the stage of coordinated management of tourism disaster risk, the coordinated management of major risks is the most important, and the process of mutual adaptation and coordination between resilience management and capacity-building for disaster prevention and mitigation is gradually showing. On the one hand, because of the tourism resilience, through the means of information technology, improve the information gathering of tourism disaster risk factors, try to control the disaster risk data information, coordinate the safe distance between the practice and virtual situation of tourism disaster risk management, give full play to the decisive role of resilience management, comprehensively stimulate the government, enterprises, social organizations and the public's ability level of risk awareness, accelerate the transformation of risk management practice to improve ability and enhance resilience. On the other hand, the risk monitoring and early warning technology of resilient governance is the supporting means to construct the functional structure system of tourism risk management, and it is the technical support to give full play to the synergy, supplement and balance ability of disaster prevention and reduction. It is particularly important to predict and analyse disasters and risks in advance and coordinate the management of the functional structure of tourism at this stage, which leads to the stagnation and even negative impact of monitoring early warning technology, which results in poor effects of disaster prevention and mitigation in tourism.

Third, in the target stage of tourism disaster risk management, the commonly used way of governance is situational reconstruction, to enhance the tourism to deal with sudden disasters and other risk disturbances. The current tourism disaster risk management has formed a identifying disaster occurrence point - simulating the construction situation - diagnosing the risk disturbance of the target-type governance model, on the one hand, the tourism disaster risk management to the process of resilient governance, will inevitably expose the phenomenon of imperfect risk management system mechanism, in the tourism industry facing disaster disturbance, disaster prevention and mitigation means innovation, the role of the government, enterprises, social organizations and other departments to take action against disaster and risk intervention and control means, take a virtual situation to take a typical disaster , simulating multi-centre governance at all stages of risk governance. These practical measures will gradually fill the gap in the institutional mechanism of tourism disaster risk management, find the gap between simulation situation and target management, and ensure the normal operation of tourism functional structure. On the other hand, the targeted management of tourism disaster risk will further induce the government, enterprises, social organizations and other multi-subjects to adopt more governance measures and management performance evaluation methods to improve the integration and innovation of resilience and disaster prevention and mitigation capabilities. This will promote the further improvement of the tourism disaster risk management system mechanism, clarify the relationship between the resilience of tourism disaster risk management and disaster prevention and mitigation capacity, from the perspective of the overall nature of the target stage of tourism disaster risk, is conducive to improving the resilience of tourism.

Finally, in the stage of communication management of tourism disaster risk, facing the transformation from government-led governance to stakeholder-oriented governance, from extensive governance to fine governance, this poses a great challenge to the new theory and function of tourism disaster risk management, and forces decision makers and multi-stakeholders to exchange risk information in a timely manner [5]. In the stage of communication-oriented governance, there has been an interdependent and complementary link between resilience management and improving disaster prevention and mitigation capabilities, and new technical 
means to deal with all kinds of risks and disasters have emerged [6]. The current risk management means lag far behind the inherent needs and technical requirements of stakeholders, which inhibits the formation of tourism disaster prevention and mitigation capacity-building and tourism resilience, which not only needs to incorporate the wisdom of stakeholders, but also strive to achieve a consensus on risk awareness, to ensure the control and predictability of tourism disaster risk management for unknown disasters, and ultimately to ensure the comprehensiveness of tourism functional structure [7].

\section{POTENTIAL DRIVERS AND BARRIERS FOR STRENGTHENING TOURISM RESILIENCE}

\subsection{Lack a Sector-wide Resilient Tourism Strategy}

To build a more resilient tourism sector, it is necessary to form sector-wide cooperation under the overall promotion of the government to promote the innovation and development of the governance model [8]. Strengthening resilience is a new paradigm of tourism disaster risk management, which can combine the structural function characteristics of tourism, construct multi-dimensional network model to spread risk, and promote the diversity, redundancy and adaptability of tourism function [9]. Through collaborative governance, one can define the boundaries of tourism disaster risk management and avoid the management workflow in the form, so that the role of the main pull mechanism of governance in tourism disaster risk management can be truly realized. Second, we can realize the diversification of governance subjects, so that the relevant subjects clear their respective responsibility structure, and really participate in the management of tourism disaster risk. Third, we can improve the structure of tourism disaster risk management, break through the bottleneck in risk management, establish correct governance concept, improve the scientific decision-making of tourism disaster risk management, so as to achieve the best overall interests of each governance subject, and promote the tourism industry to spontaneously form selfregulation, self-function adjustment risk management system.

\subsection{The Ambiguity in Tourism Resilience Governance}

In tourism disaster risk management, resilience management emphasizes the ability to resolve risks through strengthening resilience, so that tourism can still recover to its original functional structure after the disaster, and to improve the tourism disaster prevention and mitigation capacity through adaptive learning. Therefore, resilience management is an important way to promote the management of tourism disaster risk, and then it also confirms the integration of resilience management and improving the ability of tourism disaster prevention and mitigation. At present, the formulaic normality of risk management usually relies on past experience or static standard formulas when tourism is faced with uncertain disasters [10]. This confirms from a realistic point of view that tourism has not changed its basic paradigm of risk management, how to improve the ability of research and evaluation, such as risk prediction, disaster risk, potential loss, and put forward new challenges to the development of resilient tourism.

Tourism disaster risk identification is unclear, there is inconsistent between strengthening resilience and building disaster prevention and mitigation capacity. Because the risk point is not clear, in the resilient tourist attractions after the disaster, but received more resources compensation, relatively fragile tourist attractions even if they have received a small amount of resource compensation, but because of the hope for more support in the future, and choose to swallow, what's more, resilient tourist attractions falsely claim that the disaster is serious and then get more assistance." Therefore, the management of tourism disaster risk is not related to the way of governance, the effectiveness of governance depends on whether the beneficiaries affect risk identification.

With the gradual strengthening of the advantages of resilient governance, there will be many difficulties. On the one hand, this will promote the use of resilient governance to use their own innovative ideas, play the advantages of innovation into emerging technology capabilities, which will make emerging technologies further into the blocking factors of theory innovation, relatively immature long-term development of technology will lead to tourism disaster risk complex fragmentation characteristics, the overall governance capacity decline. On the other hand, compared with disaster prevention and mitigation ability, resilience management uses its own innovative paradigm to maintain its superiority in the risk chain, and because of the unpredictable and uncertain risk of tourism disaster, it inhibits the normal disaster prevention and mitigation ability in the risk chain.

\subsection{Obstacles to the Generation of the New Pattern of Tourism Disaster Risk Management}

From the internal logic of the tourism disaster risk chain, the general risk chain includes four key links: risk source identification, risk factor determination, risk detection, risk event solution. Risk hazards run through the entire risk chain. In fact, in the different links and stages of the risk chain, there are obvious differences in the tasks of risk management, functional characteristics, participants and the adapted space resource environment. Among them, the initial risk source identification stage 
of tourism disaster risk management requires not only the introduction of professionals and innovative technical means, but also innovative theoretical support and thinking logic. In the stage of risk factor determination, risk detection and risk event solution, the alignment of all links of risk chain needs the coordinated promotion of multi-participation subjects. Among them, in the special link of risk factor determination, the leading role of government is indispensable, but the participation of enterprises and the public can guarantee the feasibility of risk management. In the special link of risk detection, the risk chain has undergone fundamental changes, from the simulation of risk situation to the multi-participation of the main body using intelligent means, capital investment, talent transfer and other activities, is the development of the risk chain. Finally, in the risk event solution link, tourism disaster risk management has developed into the practice of resilient management. However, from the practical situation of tourism disaster risk management, there are not only weak points and lack of strength in the special link of the risk chain, but also the phenomenon of "blocking and metallurgy" which links and continuity of the risk chain.

\section{DISASTER PREVENTION AND MITIGATION CAPACITY - TOURISM RESILIENCE CO-GOVERNANCE STRATEGY}

The cross-integration of capacity-building of disaster prevention and reduction and resilience is a realistic need to address the tourism disasters risk management. The core of resilience governance is to emphasize the ability of tourism to survive and develop under crisis and pressure, to penetrate the concept of resilience management into tourism development planning, to cultivate people's sense of crisis and responsibility, and to apply the concept of capacity-building for disaster prevention and mitigation to the management of resilience, and to promote the diversified development of tourism disaster risk management.

\subsection{Tourism Disaster Risk Co-development Management of the New Pattern of Construction Path}

In view of the risk source identification stage in the risk chain, it is necessary to enhance and strengthen the position and role of toughness governance in this link, so as to construct a new pattern of tourism resilience governance. The low attention paid by multi-participants to the risk source identification of the risk chain and the low investment of capital lead to the vagueness of risk identification, which is the core element of the relatively weak risk response of public goods [11]. From the basic logic of the risk chain, if there is no high technical means to intervene in the risk source identification stage, it will inevitably make it difficult to improve the ability of disaster prevention and mitigation. Based on this, the government, enterprises, social organizations and other multi-participation entities to participate in risk management by means of financing, or actively establish an intelligent platform for risk management, is the basic way to solve the tourism disaster risk source identification fuzzy.

In view of the risk assessment stages such as risk factor determination, risk detection and risk event solution in the risk chain, we should comprehensively promote the co-governance of disaster prevention and mitigation capacity - tourism resilience

Actively encourage multi-subject participation in governance in the risk resolution stage. Because the risk resolution stage of the risk chain more reflects the design of the internal scheme of tourism, which is, selfregulation, self-adaptation, self-recovery, the impact of the external environment is relatively not obvious. Therefore, it is not only by strengthening the incentive mechanism, laws and regulations to replenish the status quo of insufficient resources, to improve the initiative of relevant stakeholders in the risk detection, risk event solution stage [12]. Aligning national tourism development plans with national disaster risk reduction strategies and their associated financing strategies ensures that domestic resource mobilization and development cooperation support national disaster risk reduction priorities. The private sector is crucial to play in financing capacity building of disaster prevention and mitigation in tourism sector. The right incentives can foster longer-term investments, which factor as a key performance indicator for sustainable investing and environmental, social and governance reporting. In addition, better standards and regulations are needed to guide the disclosure of disaster risk in investments and to mitigate potential negative impacts.

\subsection{Building Infrastructure Resilience}

Infrastructure service disruption costs tourism sector heavily per year. Much of this disruption is linked to disasters. Infrastructure investment is an important part of tourism resilience as it creates jobs and revitalizes communities. At the same time, the COVID-19 pandemic has shown the consequences of systematically underinvesting in tourism resilience. With COVID-19 recovery investments allocated to new infrastructure and given that the bulk of funding allocated for recovery will be used to support public investment and key structural reforms, it is critical that considerations of risk reduction and resilience shape how and where these resources are spent. 


\subsection{Ways Forward}

At present, tourism disaster risk management began to change from extensive to fine management, is no longer a single management of light prevention and heavy response, but with the development of the risk chain gradually advancing, with tourism self-recovery, adaptability, self-organization as the goal, in order to promote the improvement of tourism functional structure, so as to achieve tourism disaster risk management model innovation and structural reform. If we want to scientifically analyse the causal relationship between disaster prevention and mitigation capacity-building and tourism resilience in tourism disaster risk management, we need to integrate the functional structure and organizational form of resilience management with the overall framework of risk management as an innovative breakthrough to achieve the goal. From the specific governance structure, we should start from the internal driving force of tourism disaster risk management, in all aspects of the risk chain, promote the active link between multi-participation subjects and demand market, and optimize the allocation of regional resources for risk management. To improve disaster prevention and mitigation capacity and tourism resilience to promote the realization of a new pattern, the core task is to accurately capture the weak stage of the risk chain and the technical short board in the risk chain.

First, for the development of the tourism disaster risk chain to block the difficulties, we need to invest in the tough governance-based financial support, broaden the financing channels, timely adjustment of risk management technology platform construction. Second, set up a structured process system with risk factor determination, risk detection and risk event solution. From the technical short board faced by tourism disaster risk management, it is necessary to establish a collaborative intelligent platform for simulation of tourism risk scenarios. Third, to attract governments, enterprises, social organizations, the public and so on to actively participate in the construction of the tourism disaster risk chain, standardize the accountability management system of risk management, standardize the policy guidance mechanism of risk management, and promote the formation of a multi-share system of risk benefits in the risk resolution stage. The relevant laws and regulations, policy systems and institutional mechanisms of risk management will be concentrated on the early investment of the tourism disaster risk chain, and the standardization and proletarianization of the whole process of risk management will be promoted.

\section{CONCLUSION}

Faced with an increasingly complex and uncertain risk landscape, where climate change and systemic risks threaten tourism systems, greater understanding of the interconnected nature of hazards, exposure and vulnerability will be critical for effective disaster risk reduction and for achieving the tourism resilience goals. Take innovative thinking as a breakthrough, accelerate the innovation and transformation of tourism disaster risk management model, promote tourism resilience and disaster prevention and mitigation capacity-building advantages complement each other, ensure the seamless integration of the two, and ensure the generation of a new pattern of tourism disaster risk management. Mitigating existing risk, preventing the creation of new risk and building resilience take a whole-of-society approach. Tourism sector should develop needs-based, demand driven approaches to strengthening stakeholder capacity, including institutional implementation capacities to analyse and manage disaster and climate risks, and to strengthening risk-informed planning and risk governance mechanisms.

\section{ACKNOWLEDGMENTS}

The authors gratefully acknowledge the financial contribution to this study from research project of Sichuan Tourism Development Research Centre (No. LY21-47).

\section{REFERENCES}

[1] N. Cavlek, Tour operators and destination safety, Annals of Tourism Research 29(2) (2002) 478-496. DOI: 7383(01)00067-6 https://doi.org/10.1016/S0160-

[2] S. Becken, K. Hughey, Linking tourism into emergency management structures to enhance disaster risk reduction, Tourism Management 36 (2013) 77-85. DOI: https://doi.org/10.1016/j.tourman.2012.11.006

[3] World Bank, Rebuilding Tourism Competitiveness: Tourism Response, Recovery and Resilience to the COVID-19 Crisis, World Bank, 2020.

[4] UNISDR, Terminology on Disaster Risk Reduction, UNISDR, 2009.

[5] OECD, The Challenge of Capacity Development: Working Toward Good Practice, OECD Publishing, 2006.

[6] World Bank, Resilient industries in Japan: Lessons learned in Japan on enhancing competitive industries in the face of disasters caused by natural hazards, World Bank, 2020.

[7] World Bank, Resilient Tourism: Competitiveness in the face of disasters, World Bank, 2020.

[8] B. Faulkner, Towards a framework for tourism disaster management, Tourism Management 22(2) 
(2001) 135-147. DOI: https://doi.org/ 10.1016/S0261-5177(00)00048-0

[9] B. Ritchie, Tourism Disaster Planning and Management: From Response and Recovery to Reduction and Readiness, Current Issues in Tourism 11(4) (2008) 315-348. DOI: https://doi.org/10.1080/13683500802140372

[10]N. B. Rittichainuwat, Tourist and tourist suppliers' perception toward crisis management on tsunami, Tourism Management 34 (2013) 112-121. DOI: https://doi.org/ 10.1016/j.tourman.2012.03.018
[11] R. Law, The perceived impact of risks on travel decisions, International Journal of Tourism Research 8(4) (2006) 289-300. DOI: https://doi.org/ $10.1002 /$ jtr.576

[12] A. S. Lo, R. Law, C. Cheung, Segmenting leisure travellers by risk reduction strategies, Journal of Travel \& Tourism Marketing 28(8) (2011) 828-839. DOI:

https://doi.org/ 